\title{
Cationic Ring-Opening Copolymerization of $O$-Permethylcyclodextrin with Tetrahydrofuran
}

\author{
By Masato SUZUKI ${ }^{* \dagger}$ and Tomofumi SHIMAZAKI
}

Cationic ring-opening copolymerizations of $O$-Permethylcyclodextrins (MeCDs) with tetrahydrofuran (THF) were studied. In THF that is the comonomer as well as the solvent, MeOTf as the initiator produced the copolymer consisting of tri- $O$ methylglucopyranose and tetramethylene ether units, while $\mathrm{Et}_{3} \mathrm{O}^{+} \mathrm{PF}_{6}{ }^{-}$mainly conducted the homopolymerization of THF. The addition of $\mathrm{CH}_{2} \mathrm{Cl}_{2}$ as the cosolvent favorably promoted the polymerization of MeCDs, producing the copolymer from both initiators. Interestingly, the initiator system of $\mathrm{HI} / \mathrm{I}_{2}$ was found to chemoselectively polymerize MeCDs even in THF. KEY WORDS: Cationic Copolymerization / Ring-opening Copolymerization / Cyclodextrin / Tetrahydrofuran / Polysaccharide /

PolyTHF /

Previously, we found out that cyclodextrin derivatives can act as macrocyclic monomers for cationic ring-opening polymerization. ${ }^{1-3}$ Typically, $\alpha-, \beta$-, and $\gamma$ - $O$-permethylcyclodextrins (MeCDs) were found to produce linear $(1 \rightarrow 4)$-glucan with the aid of initiators such as $\mathrm{Et}_{3} \mathrm{O}^{+} \mathrm{X}^{-}\left(\mathrm{X}=\mathrm{BF}_{4}, \mathrm{PF}_{6}\right.$, $\mathrm{SbCl}_{6}$ ), $\mathrm{Et}_{2} \mathrm{O} \cdot \mathrm{BF}_{3}$, and $\mathrm{MeOSO}_{2} \mathrm{CF}_{3}$ (MeOTf) in $\mathrm{CH}_{2} \mathrm{Cl}_{2}$ at $0{ }^{\circ} \mathrm{C}$ to r.t. Recently, Bösch and Mischnick group is further investigating this polymerization in detail. ${ }^{4-6}$ Using cyclodextrin derivatives as scaffolds to prepare glucan-base polymers can be expanded. Thus, we are prompted to publish our data that have been orally presented in meetings. This article deals with copolymerization of MeCDs with tetrahydrofuran (THF) (Scheme 1). As suggested by literature survey, there are so many studies about cationic copolymerization of THF with other cyclic monomers, but only two articles involve the copolymer formation of THF with sugar related monomers, 1,6-anhydro-2,3,4-trimethyl- $\beta$-D-glucopyranose and anhydroalditols. ${ }^{7}$ The former monomer can produce the copolymer of glucan with THF, however, resulting in giving the cooligomer with non-selective ring-cleavage. Therefore, here is the first report for the production of the copolymer that is composed of $(1 \rightarrow 4)$-glucan with polyTHF.

\section{EXPERIMENTAL}

\section{Materials}

Three MeCDs were prepared from $\alpha-, \beta-$, and $\gamma$-CDs according to the literature, ${ }^{8}$ recrystallized twice from acetonehexane, and dried at $90{ }^{\circ} \mathrm{C}$ under vacuum. THF and $\mathrm{CH}_{2} \mathrm{Cl}_{2}$ were dried with $\mathrm{LiAlH}_{4}$ and $\mathrm{CaH}_{2}$, respectively and freshly distilled just before use. MeOTf and $\mathrm{Et}_{3} \mathrm{O}^{+} \mathrm{PF}_{6}{ }^{-}$were purified respectively by distillation from $\mathrm{P}_{2} \mathrm{O}_{5}$ and recrystallization from $\mathrm{Et}_{2} \mathrm{O}$ with $\mathrm{CH}_{2} \mathrm{Cl}_{2}$ under $\mathrm{Ar}$ atmosphere. These initiators were used as dry $\mathrm{CH}_{2} \mathrm{Cl}_{2}$ solutions (about $0.3 \mathrm{M}$ ). $\mathrm{A} \mathrm{CH}_{2} \mathrm{Cl}_{2}$ solution of $\mathrm{HI}$ was prepared by introducing $\mathrm{HI}$ gas, which was generated by dropwise addition of an aqueous solution of $\mathrm{HI}$ onto $\mathrm{P}_{2} \mathrm{O}_{5}$ and was dried through a $\mathrm{P}_{2} \mathrm{O}_{5}$ column. The concentration (about $0.5 \mathrm{M}$ ) of $\mathrm{HI}$ was determined by titration with an aqueous $\mathrm{NaOH}$ standard solution. $\mathrm{I}_{2}$ was purified by sublimation and dissolved in dry $\mathrm{CH}_{2} \mathrm{Cl}_{2}$ (about $0.3 \mathrm{M}$ ). Model compounds, $n$-butyl 4- $O$ - $n$-butyl-2,3,6-tri- $O$-methyl- $\alpha$ (and $\beta$ )D-glucopyranoside, were prepared via two steps from 2,3,6-tri$O$-methyl-D-glucopyranoside, which was prepared by hydrolysis of $\beta$-MeCD $;{ }^{9}$ two hydroxyl groups at 1 - and 4-positios were successively $O$-butylated by the acid-catalyzed condensation with $n$ - $\mathrm{BuOH}^{10}$ and then the substitution reaction to $n$-BuI in the presence of $\mathrm{NaOH} .^{11}$

\section{Polymerization}

MeCD (0.1 mmol) was dissolved in THF $(0.81 \mathrm{~mL}, 10$ mmol) (and $\mathrm{CH}_{2} \mathrm{Cl}_{2}(1 \mathrm{~mL}$ ) if necessary) under an $\mathrm{Ar}$ atmosphere. The $\mathrm{CH}_{2} \mathrm{Cl}_{2}$ solution of the initiator $(0.01 \mathrm{mmol})$ (and $\mathrm{I}_{2}(0.010 \mathrm{mmol})$ for $\left.\mathrm{HI}\right)$ was added and the mixture was stirred at r.t. for the hours stated in Tables. Afterwards, an aqueous solution of $\mathrm{NaHCO}_{3}$ was added and the aqueous layer was extracted three times with $\mathrm{CH}_{2} \mathrm{Cl}_{2}(1 \mathrm{~mL})$. When $\mathrm{I}_{2}$ was used for the polymerization, an aqueous solution of $\mathrm{Na}_{2} \mathrm{~S}_{2} \mathrm{O}_{3}$ was added before the extraction. The combined organic phase was dried with $\mathrm{MgSO}_{4}$ and concentrated to dryness. A small portion of the residue was dissolved in $\mathrm{CDCl}_{3}$ and subjected to ${ }^{1} \mathrm{H}$ NMR analysis to determine the conversion of $\mathrm{MeCD}$, the copolymer composition, and the glycoside bond ratio $(\alpha: \beta)$ of the glucopyranose unit (for details see our previous report). ${ }^{1}$ Afterwards, the $\mathrm{CDCl}_{3}$ solution was recombined with the reaction mixture, which was then dried again, dissolved in acetone $(1.1 \mathrm{~mL})$, and dropped into hexane $(30 \mathrm{~mL})$ with stirring. The precipitate was collected and dried in vacuo to give a white powdery polymer.

\section{Measurement}

GPC was carried out using a Shodex ${ }^{\circledR}$ K-803 or K-804L (Showa Denko) column, $\mathrm{CHCl}_{3}$ as the eluent, and polystyrene 


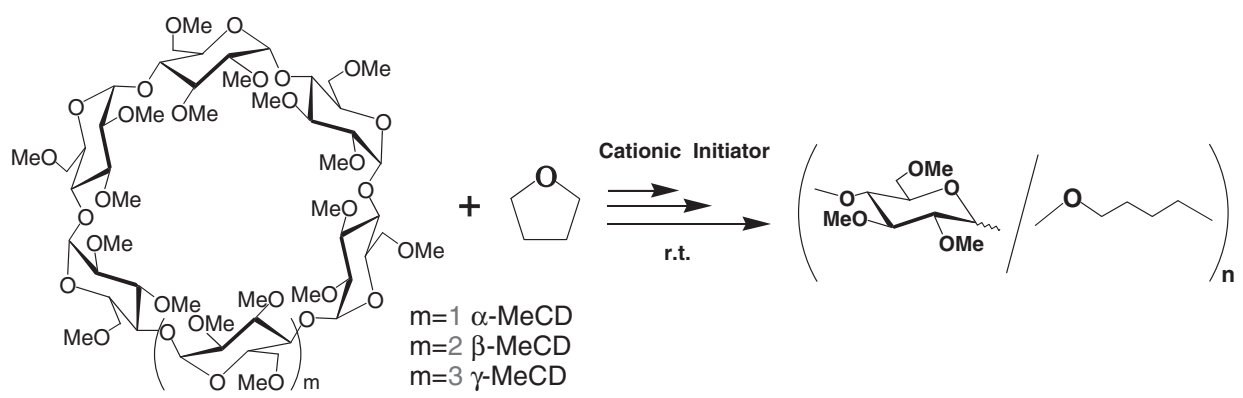

Scheme 1.

Table I. Copolymerization of MeCDs with $\mathrm{THF}^{1)}$

\begin{tabular}{|c|c|c|c|c|c|c|c|c|c|}
\hline \multirow{2}{*}{ Run } & \multirow{2}{*}{$\mathrm{MeCD}$} & \multirow{2}{*}{ Initiator 2$)$} & \multirow{2}{*}{$\begin{array}{l}\text { Time } \\
\text { (h) }\end{array}$} & \multirow{2}{*}{$\begin{array}{l}\text { Conv. of } \\
\text { MeCD } \\
(\%)^{3)}\end{array}$} & \multirow{2}{*}{$\begin{array}{c}\text { Feed of } \\
\text { MeCD } \\
(\mathrm{mg})\end{array}$} & \multirow{2}{*}{$\begin{array}{l}\text { Yield } \\
(\mathrm{mg})^{4)}\end{array}$} & \multirow{2}{*}{$\begin{array}{c}\text { Unit ratio } \\
\text { glucose: } \mathrm{THF}^{3)}\end{array}$} & \multicolumn{2}{|c|}{ GPC $^{5)}$} \\
\hline & & & & & & & & $M_{\mathrm{n}}$ & $M_{\mathrm{w}} / M_{\mathrm{n}}$ \\
\hline 1 & $\alpha$ & MeOTf & 24 & 27 & 121 & 60 & $9: 91^{6)}$ & \multicolumn{2}{|c|}{$M_{p}=49500,8000^{7)}$} \\
\hline 2 & $\beta$ & & 16 & 95 & 143 & 178 & $17: 83^{6)}$ & \multicolumn{2}{|c|}{$M_{p}=67400,6500^{7)}$} \\
\hline 3 & $\gamma$ & & 24 & 95 & 168 & 114 & $72: 28^{8)}$ & 2700 & 1.79 \\
\hline 4 & $\alpha$ & $\mathrm{Et}_{3} \mathrm{OPF}_{6}$ & 0.5 & 0 & 123 & 94 & $0: 100$ & 50000 & 1.37 \\
\hline 5 & $\beta$ & & 0.5 & 0 & 145 & 81 & $0: 100$ & 58600 & 1.23 \\
\hline 6 & $\gamma$ & & 0.5 & 0 & 163 & 51 & $0: 100$ & 97700 & 1.38 \\
\hline 7 & $\gamma$ & & 1 & 7 & 165 & 44 & $3: 97^{6)}$ & 62900 & 1.42 \\
\hline 8 & $\gamma$ & & 3 & 51 & 165 & 296 & $7: 93^{6)}$ & \multicolumn{2}{|c|}{$\left.M_{p}=113000,9400^{7}\right)$} \\
\hline
\end{tabular}

1) MeCD: $0.1 \mathrm{mmol}$; THF: $0.81 \mathrm{~mL}(10 \mathrm{mmol})$; r.t. 2) $[\mathrm{MeCD}] /\left[\right.$ Initiator] $=10$. 3) Calculated from ${ }^{1} \mathrm{H}$ NMR spectra. 4) After precipitation from acetone to hexane. 5) Polystyrene standard, $\mathrm{CHCl}_{3} .6$ ) The TLC analysis indicated that the homopolymer of THF was contained. 7) Bimodal peaks topped at the molecular weight of Mp. 8) Ratio of the glycoside bond $\alpha: \beta=80: 20$.

standards. The GPC elution profiles were recorded by a RI (refractive index) detector (Shimadzu RID-10A) or the combination of RI and OR (optical rotation) detectors (JASCO RI-1530 and OR-1590). ${ }^{1} \mathrm{H}$ NMR spectra were measured in $\mathrm{CDCl}_{3}$ by a Bruker DPX 300 spectrometer. TLC was performed on an aluminum plate coated with Silica gel 60 $\mathrm{F}_{254}$ (Merck) using acetone $/ \mathrm{H}_{2} \mathrm{O}(2: 1 \mathrm{v} / \mathrm{v})$ as the mobile phase and the mixture of $p$-anisaldehyde $/ \mathrm{H}_{2} \mathrm{SO}_{4} / \mathrm{CH}_{3} \mathrm{CO}_{2} \mathrm{H} / \mathrm{EtOH}$ for detection.

\section{RESULTS AND DISCUSSION}

\section{Copolymerization in THF}

As the first investigation, the cationic polymerizations of MeCDs were conducted in THF, which works as not only the solvent but also the comonomer (Table I). The initiators are MeOTf and $\mathrm{Et}_{3} \mathrm{O}^{+} \mathrm{PF}_{6}{ }^{-}$, both of which are known to effectively initiate the homopolymerization of either MeCDs or THF at r.t. The polymers produced with MeOTf (Runs 1 3) contained both of tri- $O$-methylglucopyranose and tetramethylene ether units, whose relative contents were evaluated by ${ }^{1} \mathrm{H}$ NMR spectroscopy. Figure 1 shows the ${ }^{1} \mathrm{H}$ NMR spectra of the copolymer prepared at run 3 . There are observed the distinguishable signals due to the copolymer units at $\delta 4.2 \sim 5.8$ $\left(\mathrm{H}_{1}\right)$ and $1.6 \mathrm{ppm}$ (a). The integral ratio of these signals was helpful to calculate the copolymer composition. Some small signals besides those $\left(\mathrm{H}_{\alpha}\right.$ and $\left.\mathrm{H}_{\beta}\right)$ due to the homopolymer units from $\mathrm{MeCD}^{1}$ were detected in the area of $\delta 4.2 \sim 5.8 \mathrm{ppm}$.
Considering the chemical shift of the anomeric proton of a model compound, $n$-butyl 4- $O$ - $n$-butyl-2,3,6-tri- $O$-methyl- $\alpha$-Dglucopyranoside (Figure 1), they are assignable but not precisely identified to $\mathrm{H}_{1}$ protons of the linking position between glucopyranose and tetramethylene ether units $\left(\mathrm{H}_{\alpha-\mathrm{THF}}\right)$ and of terminal groups.

A GPC system equipped with refractive index (RI) and optical rotation (OR) detectors gave further information about the compositions of the product polymers. The former detector is sensitive for both of the glucopyranose and tetramethylene ether units, while the latter senses only the glucopyranose unit. Two kinds of GPC profiles given by these detectors are shown in Figure 2a for the crude products from run 2 in Table I. Each of them has three peaks due to the product polymers with unreacted $\beta$-MeCD, but it should be noted that the relative peak intensities are different. The second elution peak in the OR detector profile is bigger than the first, while it is the opposite in the RI detector profile. This finding suggests that the tetramethylene ether unit is much more contained in the higher molecular weight part of the product polymers. On the other hand, in Figure 2b, GPC profiles given by two detectors show almost the same shapes for run 3, suggesting that the product copolymer has the homogenous composition.

TLC analyses (acetone: $w a t e r=2: 1 \mathrm{v} / \mathrm{v}$ ) are also informative for the compositions of the product polymers (Figure 3 ). The homopolymer of THF is fixed at the position originally spotted, whereas $\beta$-MeCD and its homopolymer are moved up to much higher positions. On the TLC plate for run 2 , the 


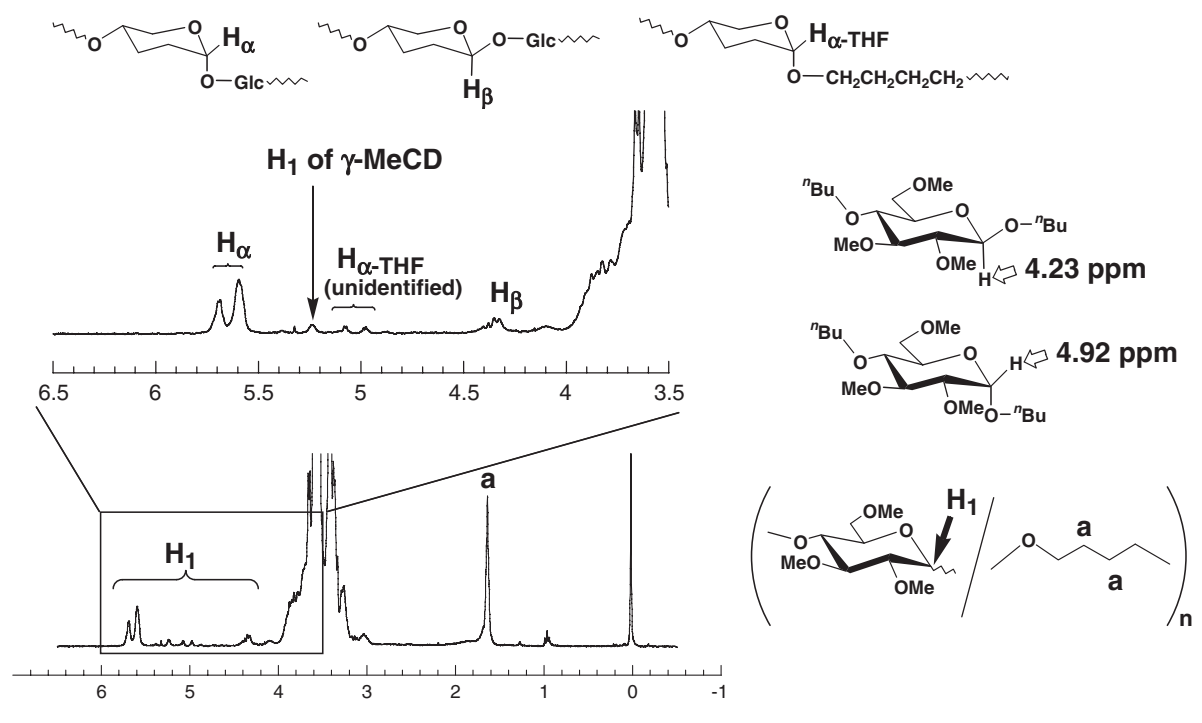

Figure 1. ${ }^{1} \mathrm{H}$ NMR spectra $\left(\mathrm{CDCl}_{3}\right)$ of the copolymer from run 3 (Table I).
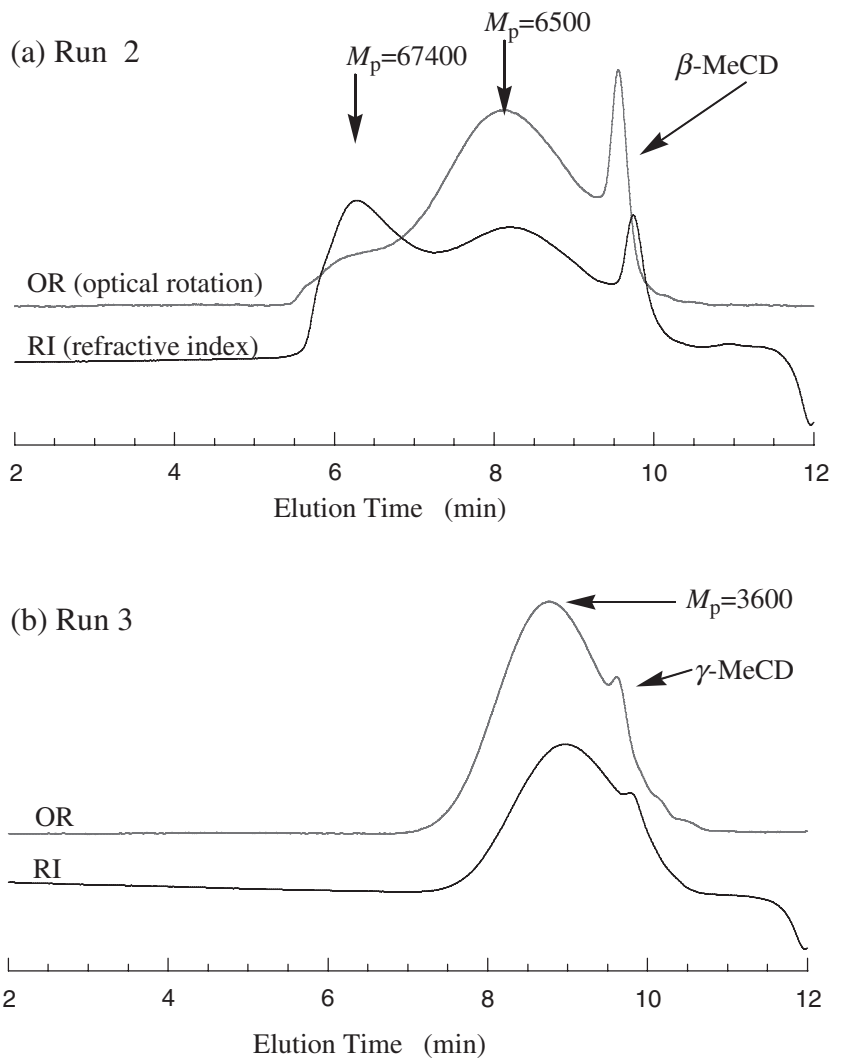

Figure 2. GPC profiles of runs 2 (a) and 3 (b) in Table I.

original spot was developed as a line. On the other hand, the product of run 3 showed a similar chromatogram to the homopolymer of MeCD. These findings are in good agreement with the above results suggested by GPC; the THF homopolymer or the THF-rich copolymer was produced at run 2 but not at run 3 . This difference is attributable to the higher polymerizability of $\gamma$-MeCD (run 3) than $\beta$-MeCD (run 2). ${ }^{1}$
As compared with the initiator of MeOTf (runs 1-3), $\mathrm{Et}_{3} \mathrm{O}^{+} \mathrm{PF}_{6}{ }^{-}$promoted the polymerization more effectively and the reaction mixture became highly viscous within $30 \mathrm{~min}$ (runs 4-6, Table I). However, the product polymers were found to be the homopolymer of THF. Increasing the reaction time increased the conversion of $\gamma$-MeCDs, but the product polymer was mainly composed of the tetramethylene ether unit (runs 7 and 8). The difference between $\mathrm{Et}_{3} \mathrm{O}^{+} \mathrm{PF}_{6}{ }^{-}$and MeOTf as the initiator is most likely ascribable to that in the character of the propagating end. As is well known in the ring-opening polymerization of THF, the propagating end initiated with MeOTf is in the equilibrium between the oxonium and the trifrate ester. Thus, the polymerization of THF with MeOTf is slower and thus MeCDs can get a chance to participate in the polymerization.

\section{Copolymerization in $\mathrm{CH}_{2} \mathrm{Cl}_{2}$}

The copolymerization was performed in $\mathrm{CH}_{2} \mathrm{Cl}_{2}$ under the conditions where the living polymerization of THF takes place. ${ }^{12}$ In contrast with the copolymerization in THF, MeCDs were polymerized well and rather predominantly incorporated into the copolymers (Table II). The TLC analysis suggested that the homopolymer of THF was hardly produced in all runs. Among three MeCDs, the polymerizability decreased in the order of $\gamma^{-}, \beta-$, and $\alpha-$; this is the same as the previous findings in the homopolymerization of MeCDs. ${ }^{1}$ The last column of Table II shows the stereo chemistry of the glycoside linkage of the product polymers. As is discussed in our previous papers, ${ }^{1-3}$ the high contents of the $\alpha$-glycoside linkage over $90 \%$ suggests that the acetal exchange reaction hardly takes place in these runs. ${ }^{13}$ This is in contrast with the previous finding that the acetal exchange reaction is involved in the homopolymerization of MeCDs in $\mathrm{CH}_{2} \mathrm{Cl}_{2} .{ }^{1}$ The difference is elucidated by a solvent effect; the copolymerization is virtually conducted in the mixed solvent of $\mathrm{CH}_{2} \mathrm{Cl}_{2}$ with THF, which is less polar than $\mathrm{CH}_{2} \mathrm{Cl}_{2}$ and thus retards the acetal exchange reaction. 


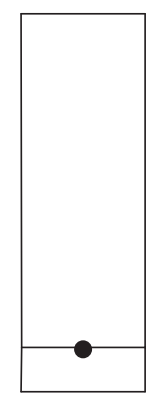

Homopolymer of THF

$\left(M_{\mathrm{n}}=4000\right)$

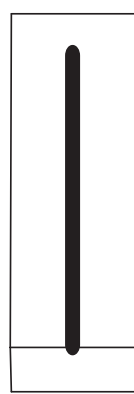

Run 2

(Table I)

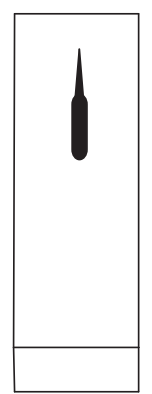

Run 3

(Table I)

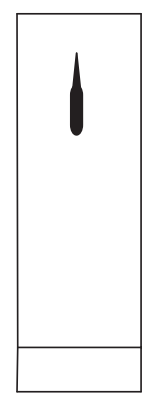

Homopolymer of $\beta$-MeCD $\left(M_{\mathrm{n}}=3800\right)$

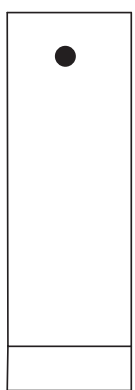

$\beta$-MeCD

$\left(\mathrm{R}_{\mathrm{f}}=0.91\right)$

Figure 3. TLC analyses of the polymers and MeCD (silica gel $60 \mathrm{~F} 254$, developed with acetone/water $(2 / 1 \mathrm{v} / \mathrm{v})$, detected with $p$-anisaldehyde/ $\mathrm{H}_{2} \mathrm{SO} \mathrm{O}_{4} /$ $\mathrm{CH}_{3} \mathrm{CO}_{2} \mathrm{H} / \mathrm{EtOH}$ ).

Table II. Copolymerization of MeCDs with THF in $\mathrm{CH}_{2} \mathrm{Cl}_{2}{ }^{1)}$

\begin{tabular}{|c|c|c|c|c|c|c|c|c|c|c|}
\hline \multirow{2}{*}{ Run } & \multirow{2}{*}{$\mathrm{MeCD}$} & \multirow{2}{*}{ Initiator ${ }^{2)}$} & \multirow{2}{*}{$\begin{array}{l}\text { Time } \\
\text { (h) }\end{array}$} & \multirow{2}{*}{$\begin{array}{l}\text { Conv. of } \\
\text { MeCD } \\
(\%)^{3)}\end{array}$} & \multirow{2}{*}{$\begin{array}{c}\text { Feed of } \\
\text { MeCD } \\
(\mathrm{mg})\end{array}$} & \multirow{2}{*}{$\begin{array}{l}\text { Yield } \\
(\mathrm{mg})^{4)}\end{array}$} & \multirow{2}{*}{$\begin{array}{c}\text { Unit ratio } \\
\text { glucose:THF }\end{array}$} & \multicolumn{2}{|c|}{$\mathrm{GPC}^{5}$} & \multirow{2}{*}{$\begin{array}{c}\text { Ratio of } \\
\text { glycoside } \\
\text { bond } \\
\alpha: \beta^{3)}\end{array}$} \\
\hline & & & & & & & & $M_{\mathrm{n}}$ & $M_{\mathrm{w}} / M_{\mathrm{n}}$ & \\
\hline 9 & $\alpha$ & MeOTf & 48 & 80 & 123 & 87 & $87: 13$ & 2900 & 1.47 & $80: 20$ \\
\hline 10 & $\beta$ & & 24 & 95 & 145 & 166 & $80: 20$ & 4400 & 1.61 & $94: 6$ \\
\hline 11 & $\gamma$ & & 24 & 97 & 166 & 160 & $88: 12$ & 3500 & 1.50 & $96: 4$ \\
\hline 12 & $\alpha$ & $\mathrm{Et}_{3} \mathrm{OPF}_{6}$ & 48 & 47 & 122 & 61 & $48: 52$ & 4300 & 1.60 & $87: 13$ \\
\hline 13 & $\beta$ & & 48 & 58 & 144 & 99 & $68: 32$ & 4600 & 1.98 & $92: 8$ \\
\hline 14 & $\gamma$ & & 24 & 98 & 167 & 174 & $85: 15$ & 7000 & 1.83 & $92: 8$ \\
\hline
\end{tabular}

1) MeCD: $0.1 \mathrm{mmol}$; THF: $0.81 \mathrm{~mL}(10 \mathrm{mmol}) ; \mathrm{CH}_{2} \mathrm{Cl}_{2}: 1 \mathrm{~mL}$; r.t. 2) $[\mathrm{MeCD}] /\left[\right.$ Initiator] = 10. 3) Calculated from $\left.{ }^{1} \mathrm{H} \mathrm{NMR} \mathrm{spectra.} 4\right)$ After precipitation from acetone to hexane. 5) Polystyrene standard, $\mathrm{CHCl}_{3}$.

Table III. Copolymerization of MeCDs with THF by the $\mathrm{HI} / \mathrm{I}_{2}$ initiator system ${ }^{1)}$

\begin{tabular}{|c|c|c|c|c|c|c|c|c|}
\hline Run & $\mathrm{MeCD}$ & Solvent & $\begin{array}{c}\text { Conv. of } \\
\operatorname{MeCD}(\%)^{2)}\end{array}$ & $\begin{array}{l}\text { Yield } \\
(\%)^{3)}\end{array}$ & $\begin{array}{c}\text { Unit ratio } \\
\text { glucose:THF }\end{array}$ & $M_{\mathrm{n}}$ & $M_{\mathrm{w}} / M_{\mathrm{n}}$ & $\begin{array}{c}\text { Ratio of } \\
\text { glycoside bond } \\
\alpha: \beta^{2)}\end{array}$ \\
\hline 15 & $\alpha$ & THF & 11 & trace & & & & \\
\hline 16 & $\beta$ & & 32 & 18 & 100:0 & \multicolumn{2}{|c|}{$M_{p}=4800,3300,1800^{5)}$} & $94: 6$ \\
\hline 17 & $\gamma$ & & 49 & 44 & $100: 0$ & 3500 & 1.50 & $94: 6$ \\
\hline 18 & $\alpha$ & $\mathrm{THF} / \mathrm{CH}_{2} \mathrm{Cl}_{2}$ & 21 & 10 & 100:0 & \multicolumn{2}{|c|}{$M_{p}=2600,1470^{5)}$} & $100: 0$ \\
\hline 19 & $\beta$ & & 37 & 18 & $100: 0$ & \multicolumn{2}{|c|}{$M_{\mathrm{p}}=3500,1700^{5)}$} & $95: 5$ \\
\hline 20 & $\gamma$ & & 63 & 52 & 100:0 & 7000 & 1.83 & $95: 5$ \\
\hline
\end{tabular}

1) MeCD: $0.1 \mathrm{mmol}$;HF: $0.81 \mathrm{~mL}(10 \mathrm{mmol}) ; \mathrm{CH}_{2} \mathrm{Cl}_{2}: 1 \mathrm{~mL} ; \mathrm{HI} / \mathrm{I}_{2}$ (1:1): $0.01 \mathrm{mmol}$ r.t.; $48 \mathrm{~h} .2$ ) Calculated from ${ }^{1} \mathrm{H} \mathrm{NMR}$ spectra. 3 ) After precipitation from acetone to hexane. 4) Polystyrene standard, $\mathrm{CHCl}_{3}$. 5) $\mathrm{Bi}$ - or tri-modal peaks topped at the molecular weight of $\mathrm{Mp}$.

\section{Copolymerization initiated with $\mathbf{H I} / \mathbf{I}_{2}$}

As described in our previous paper, the combination of HI with $\mathrm{I}_{2}$ is a good system to control the homopolymerization of $\mathrm{MeCDs}$ in $\mathrm{CH}_{2} \mathrm{Cl}_{2}{ }^{2}$. Therefore, this initiator system was applied to the copolymerization (Table III). Consequently, it was found that THF was not polymerizable under these conditions. The $\mathrm{HI} / \mathrm{I}_{2}$ system successfully conducted the chemoselective cleavage and recombination of the glycoside linkage, i.e., a kind of acetal, of MeCDs, producing the polymer exclusively composed of the glucopyranose unit. In the same manner as found in our previous study, ${ }^{2}$ the GPC profiles showed the multi modal peaks due to the oligomers at the low monomer conversions.
Acknowledgements. The authors greatly thank JASCO Corporation for the GPC measurement with the combination of RI and OR detectors. M. S. expresses his gratitude to The Ministry of Education, Science, Sports and Culture, Japan for the financial support by Grant-in-Aid for Scientific Research (No. 11650904).

Received: February 7, 2008 Accepted: April 4, 2008 Published: May 28, 2008

\section{REFERENCES}

1. M. Suzuki, O. Numata, and T. Shimazaki, Macromol. Rapid Commun., 22, 1354 (2001). 
2. M. Suzuki and T. Shimazaki, Org. Biomol. Chem., 1, 604 (2003).

3. M. Suzuki, O. Numata, and T. Shimazaki, Macromol. Symp., 215, 255 (2004).

4. R. Adden, A. Bösch, and P. Mischnick, Macromol. Chem. Phys., 205, 2072 (2004).

5. A. Bösch, M. Nimtz, and P. Mischnick, Cellulose, 13, 493 (2006).

6. A. Bösch and P. Mischnick, Biomacromolecules, 8, 2311 (2007).

7. J. Thiem and W. A. Strietholt, Macromol. Chem. Phys., 196, 1487 (1995) and references cited therein.

8. G. Schomburg, A. Deege, H. Hinrichs, E. Hübinger, and H. Husmann, J. High Resolut. Chromatogr., 15, 579 (1992).

9. A. Kanazawa, S. Okumura, and M. Suzuki, Org. Biomol. Chem., 3,
1746 (2005). The procedure used therein for the hydrolysis of the O-methylated glucan was employed.

10. G. N. Bollenback, Meth. Carbohydr. Chem., 2, 326 (1963). The procedure used therein for the formation of methyl glucoside was applied.

11. The $O$-methylation procedure for $\mathrm{CD}$ mentioned in ref 8 was employed.

12. S. Kobayashi, H. Uyama, M. Ogaki, T. Yoshida, and T. Saegusa, Macromolecures, 22, 4412 (1989).

13. The detailed mechanism and discussion of the acetal exchange reaction are available in refs 2 and 3. 